\title{
"El agua no se le niega a nadie" \\ Estudio social sobre la prevención del dengue en un barrio de Clorinda, Formosa, nordeste argentino*
}

\author{
Andrea Mastrangelo**
}

\section{Resumen}

Este artículo reflexiona, con base en un estudio de caso una localidad de Formosa, sobre las tensiones entre individuo y estructura social en una campaña de vigilancia y control del vector del dengue.

El método fue la etnografía. Se aplicaron entrevistas grupales, grupos focales y registros fotográficos en campo con agentes sanitarias de una ONG local dedicada a la prevención. Asimismo, se residió en un barrio donde se tomaron entrevistas abiertas con doble registro (en formulario estructurado y grabación) a una muestra no probabilística de 61 responsables domésticos del agua de consumo. El campo se completó con entrevistas abiertas para caracterizar el sistema de agua potable de la ciudad.

Se concluye que la persistencia de criaderos de mosquitos en el barrio está más relacionada con deficiencias en el aprovisionamiento regular de agua por red que con la voluntad individual o familiar de tapar los recipientes. Se pone en evidencia cómo las representaciones de la comunidad de los programas de prevención opacan carencias estructurales, limitando la eficacia de las medidas de control.

\footnotetext{
* Artículo recibido el 25 de marzo de 2013. Aceptado el 23 de junio de 2013.

** Andrea Mastrangelo es Doctora en Antropología Social por la Universidad Nacional de Misiones. CONICET - FLACSO Argentina.

Contacto: andreaveronicamastrangelo@gmail.com
} 


\section{Palabras clave}

Dengue - prevención - agua potable.

\section{Abstract}

The aim of this paper is to contribute to understand the relationship between individual performance and social structure in a dengue's vector control program held by a NGO in a middle size city in Formosa, Northeastern, Argentina.

Research method was ethnography. Focus group, group interviews and pictures were taken with NGO sanitary agents. Main researcher move to a neighbourhood where was held a survey to a non probabilistic sample (61 domestic units). Meanwhile survey was registered, in deep interviews to domestic tag water responsibles were recorded. Fieldwork was completed with open interviews to characterize tag water supply.

In conclusion we affirm persistence of mosquitoes breeding sites is more related with city insufficient water supply than with familiar voluntee to cover water containers. We support sanitary agents social discourse on community darken this estructural shortage, reducing finally, control measures efficacy.

\section{Keywords}

Dengue fever - prevention - tag water supply.

\section{Introducción}

En toda la ciudad, durante cinco ciclos focales de descacharrado, búsqueda activa de criaderos y aplicación de larvicida, el 55 \% de los criaderos de vectores permanecieron en recipientes del grupo $B$ (tanques para el almacenamiento de agua con capacidades de 200 a 500 litros) y $\mathrm{F}$ (aljibes y cisternas de gran capacidad, más de 5000 litros). De todos los barrios donde se realizaban campañas de control, los ojos de los agentes sanitarios se fijaban en Terete ${ }^{1}$. Situado lejos de la costa del río, el barrio aparecía aislado de la influencia de variables ambientales ¿Qué pasa allí?, se preguntaban junto a los agentes sanitarios. ¿Hay alguna variable sociocultural que pueda explicar la

$1 \quad$ Nombre ficticio. 
persistencia de los criaderos? ¿Es un barrio predominantemente indígena? ¿Es el lugar donde llegan a radicarse migrantes rurales?

Esta fue la razón por la que se convocó a una antropóloga para realizar una investigación etnográfica. Para estudiar la residualidad del larvicida utilizado en los ciclos focales ${ }^{2}$ en ese barrio, un biólogo había diseñado una muestra al azar no probabilística de 64 recipientes $\mathrm{B}$ y $\mathrm{F}$ ubicados en los patios de 61 unidades domésticas (Garelli et al., 2011). Para entender por qué estos grandes reservorios estaban dispersos en el barrio, por qué y para qué usos se guardaba el agua que contenían, la investigadora social residió durante una semana en una casa de familia del barrio y superpuso sus recorridos con los del personal sanitario.

Este artículo resume lo allí encontrado. En una primera sección se sistematiza el Discurso del Sujeto Colectivo (Lefevre y Lefevre Cavalcanti, 2007) de los agentes sanitarios sobre el barrio, el dengue y el agua que se guarda en las casas. En un segundo acápite se describe por qué las familias del barrio continuaban guardando agua aun cuando existe una red por cañerías de agua potable. Por último, se reflexiona, en diálogo con otros estudios sobre la causalidad social (Stoddard et ál., 2013; Suárez et ál., 2009; Caprara et ál., 2009; Mondini y Chiaravallotti Neto, 2007; Caballero Hoyos et ál., 2006; Fajardo et ál., 2001; Whiteford, 1997) a la hora de comprender limitaciones de las estrategias de prevención del dengue en América Latina.

El artículo presenta la información obtenida, de modo que pueda ser usada para reflexionar sobre las tensiones entre sujeto y estructura social, en el momento de evaluar la eficacia de algunas medidas sanitarias a escala microfocal.

\section{"Saber cuidar el agua", el discurso del sujeto colectivo en los agentes sanitarios}

El trabajo de campo etnográfico posibilitó la sistematización de cuatro representaciones sociales sobre el agua de uso doméstico en el barrio entre los equipos técnicos y agentes sanitarios. Estas se ordenaron aplicando la técnica cualicuantitativa del Discurso del Sujeto Colectivo (Lefevre Cavalcanti, 2007). Esta técnica da visibilidad a la iteración de los hablantes, sin la intervención metadiscursiva

2 Las campañas de prevención del dengue estudiadas en este caso están organizadas en monitoreos entomológicos que se realizan recorriendo uno por uno domicilios y espacios públicos (plazas, calles, baldío, cementerios, etc.). La finalidad de estos recorridos es la búsqueda activa de larvas de vector. Los agentes sanitarios las identifican y, cuanto es posible, las remueven, recolectando una muestra para el laboratorio. En algunos casos en los que no se puede eliminar el criadero, se disuelve larvicida (Temefos) en el recipiente. Sobre la base del registro de estos datos y la determinación específica en el laboratorio, se establece un índice de infestación utilizado para medir el riesgo de infección. Los ciclos focales se organizan por secciones o recorridos de porciones del territorio. Un ciclo focal completo es la recorrida sistemática de toda la planta urbana en un período con ciertas características ambientales (por ejemplo, los meses con mayor temperatura/humedad o sequía).

http://www.msal.gov.ar/dengue/images/stories/pdf/boton-

institucional/directrices/guia_\%20acciones\%20_prevencion_control_aedes\%20_aegypti.pdf.

Las propuestas académicas de programas de prevención adoptan dinámicas semejantes, proponiendo el empoderamiento o participación de la comunidad por diferentes medios (Schweigmann et ál., 2013). 
del investigador. De esta manera, se busca evitar convertir a las opiniones en meras variables cuantificadas, mutilando su naturaleza discursiva. El carácter social del discurso permite considerar la recurrencia de enunciados individuales como hecho colectivo o como enunciados de la estructura social (Bourdieu en Lefrevre y Lefevre Cavalcanti, 2007).

\section{Discurso del Sujeto Colectivo I: "El problema es la gente del barrio"3}

En las entrevistas a técnicos, funcionarios municipales y agentes sanitarios fue recurrente la sospecha de un "problema cultural", "ignorancia" o "una cuestión de valores" que llevaba a las familias al consumo indiscriminado y de cualquier origen del agua. Probablemente por influencia de este discurso colectivo fue que los investigadores seleccionamos como lugar del estudio al barrio más lejano respecto del centro, y hacia donde se expande la ciudad. A la vez, la consideración de variables ambientales (la lejanía de la costa del río) teñía esta elección: pensábamos al barrio como una frontera o confín de la ciudad, un lugar alejado y con carencias.

Sin embargo, estos supuestos fueron desbaratados por los responsables del agua en los hogares del barrio. La totalidad de las entrevistas de la muestra de hogares de Terete mostró complejidad en los arreglos para almacenar agua, para proveer de agua por red al interior de la vivienda o para garantizar la calidad del agua de consumo. Asimismo, encontramos una o varias personas responsables de mantener abastecido de agua el domicilio. Estos responsables del abastecimiento pudieron argumentar criterios de manejo para garantizar caudal y calidad en el agua de consumo, aun cuando el criterio de calidad y cuidado de algunos pobladores no coincidía con los parámetros de potabilidad y saneamiento consensuados por la prevención.

La información recolectada en terreno permitió precisar que el acopio en los patios se intensificó por la mala calidad de servicio de la red de agua potable, más que cualquier otra razón. El testimonio de una vecina de la última calle planificada del ejido urbano es especialmente claro a este respecto:

Cuando tenía agua de bomba -agua subterránea con bombeo manual- tenía el tanque en el patio, pero no guardaba. Tenía para el día, para sacar un balde para el baño, para limpiar la casa. Ahora cuando vino el agua potable empecé a guardar porque se corta. Y con los chicos no se puede estar sin agua. (Abierta Mbl)

3 Citas informantes: "A la gente del barrio le da lo mismo lo que se haga con el agua, no le importa tener cuidado" (agente sanitaria). "La gente guarda el agua porque no tiene instrucción y las creencias que tiene sobre el agua que no se condicen con la realidad" (técnico cooperativa de agua potable). 


\section{Discurso del Sujeto Colectivo II: "La preferencia de tomar agua de lluvia es de los viejos" 4}

Entre los agentes sanitarios se repitió en varias instancias que el cuidar del agua de consumo y guardarla en recipientes es una costumbre tradicional, más frecuente en las personas mayores que han pasado gran parte de su vida sin acceso al agua potable o provienen de medios rurales. Se trataría de un hábito en los ancianos que está siendo superado por la educación escolar y la información en las nuevas generaciones.

Sin embargo, al analizar las opiniones de la encuesta, de un total de 61 unidades domésticas, solamente seis hogares, un $9 \%$ del total, expresó preferencia por consumir agua de lluvia aun cuando cuenten con agua potable de red dentro del domicilio. En estos casos, el rechazo al agua potable de red y la preferencia por consumir agua de lluvia no dependía unívocamente de la edad, de la educación ni del ingreso de los entrevistados. El olor y el gusto fueron los factores determinantes para rechazar el agua tratada: "Pone oscuro el (mate) cocido; lava el mate. Es horrible. Por eso prefiero el agua de lluvia para tomar y para cocinar" (Rec. 25 y 26).

Aun cuando no implicara la sustitución por agua de otros orígenes, el cloro fue informado como factor de rechazo con mayor frecuencia que los sólidos suspendidos.

En los grupos focales los agentes de campo informaron que "a veces la gente dice que las larvas ("isocambõ" en guaraní) vienen por las cañerías de agua" tratada. Este es otro indicio que muestra que los pobladores locales no confían en que el agua potable sea limpia, y por tanto, saludable.

Por otra parte, existe un vocablo guaraní que designa al agua de lluvia guardada: "amandícurê". Su traducción literal es "el agua que cayó en gotas" y sobre este agua los pobladores del barrio no señalaron efectos negativos para la salud. En las décadas del 60 y 70, antes del diseño de la red de agua potable, el "amandícurê" solía guardarse en cántaros de barro semienterrados en los patios o en el interior de las viviendas, para conservarla fresca para el consumo (Focus group con agentes sanitarios). Estas prácticas asociadas con la historia y el gusto local persisten en algunas de las unidades domésticas de la muestra (como $\operatorname{Rec} 13,21,25,26$ ), que usan el agua tratada de la cañería en la descarga de la cocina y el baño, mientras que prefieren para consumo humano (tomar y cocina) el agua de lluvia.

4 Citas informantes: "los viejitos son los que cuidan mejor el agua" (agente sanitaria a); "la preferencia de tomar agua de lluvia es de los viejos" (agente sanitaria b). 


\section{Discurso del Sujeto Colectivo III: "La conexión al agua potable es de bajo costo, solo hay que pagar los materiales"}

A pesar de los subsidios y las políticas de erradicación de la pobreza estructural, el costo de la conexión a la red de agua y el mismo consumo de agua son cargas pesadas en el presupuesto de los hogares del barrio. En Formosa el $30 \%{ }^{5}$ de la población urbana está debajo de la Línea de Pobreza. Para este grupo de pobladores del barrio, la conexión a la red de agua podría costar entre un 39 \% y un 78 \% de su ingreso ${ }^{6}$.

En lo que respecta al gasto por consumo de agua, hay en el barrio 1248 lotes conectados a la red que reciben factura. En la administración de la cooperativa todos estos usuarios tienen demoras en el pago. Las deudas que se reclaman van desde $\$ 0,05$ hasta $\$ 407,88$. Este último usuario/a debe el equivalente a 81 meses de facturación (casi siete años). Deben más de cinco meses de facturación el $3 \%$ de los usuarios. Estas demoras en el pago entre los usuarios domésticos dan dimensión de cómo el costo del agua incide en los presupuestos familiares.

El precio del agua que se consume incluye otra iniquidad: las empresas contratistas de obra pública en los barrios pagan un canon fijo mensual (\$480) por toda el agua que utilizan, a la vez que utilizan agua de la red para elaborar las mezclas de áridos.

\section{Discurso del Sujeto Colectivo IV "El dengue es una enfermedad de la pobreza"}

El análisis de las limitaciones de infraestructura de la red de agua potable en Clorinda permite inferir que los cortes imprevistos llevan a generalizar el acopio de agua en recipientes tipo $\mathrm{B}$ o $\mathrm{F}$ en toda la ciudad, sin diferenciación por condición socioeconómica.

Como señalaron investigaciones anteriores (Neto et ál. 2006; Passos, 19987), las resistencias a la vigilancia y control son las que pueden diferenciarse por ingreso, pero no las condiciones ambientales que posibilitan el desarrollo de criaderos. En efecto, las unidades domésticas del barrio donde se realizó el estudio no acopian agua "porque

5 A mayo de 2008 , el $20 \%$ de los hogares y el $30 \%$ de las personas que residen en zona urbana en Formosa estaban debajo de la línea de pobreza, fijada en \$316 (INDEC, EPH 2009).

$6 \quad$ El costo de conexión a la red incluye los materiales, por lo que varía según la distancia entre el caño de distribución troncal y el domicilio que hay que conectar.

$7 \quad$ "Curiosamente, la mayor resistencia a las medidas procedían de los dos extremos de población. Por un lado, las personas que viven en las zonas periféricas, especialmente de pobres, el medio ambiente contaminado de los barrios marginales, con el predominio de los sitios de reproducción se deriva (...) de las condiciones de miseria de los propios habitantes. Por el otro, paradójicamente, los barrios de mayores ingresos tienden a ser más reticentes (...) a aceptar sugerencias para evitar los sitios de reproducción (como plantas de maceta y piscinas)" (Passos, 1998). $8 \quad$ En los censos nacionales de Argentina se define como casa "tipo A" a la vivienda con salida directa al exterior (sus moradores no pasan por patios, zaguanes o corredores de uso común). En contraposición con la casa tipo B, que cumple por lo menos una de las siguientes condiciones: no tiene provisión de agua por cañería dentro de la vivienda; no dispone de retrete con descarga de agua; tiene piso de tierra u otro material precario. El resto de las casas es considerado como casas tipo A. 
son pobres", "son ignorantes y no saben", "son sucios" o "respetan una costumbre de sus antepasados", lo hacen porque la cooperativa de agua potable presta un servicio insuficiente. Esto es, en los patios del barrio Terete se acopia agua por un déficit de infraestructura urbana de la ciudad de Clorinda. Y si hay mayor incidencia de dengue entre la población de menor ingreso es porque la pobreza aumenta la exposición al riesgo, pero no porque en las casas de más altos ingresos no haya criaderos de Aedes aegypti.

Es importante precisar esto, ya que, como señala Mary Douglas (1994), el control del riesgo de las enfermedades suele ser complementario de la noción de higiene interpretada en términos morales y políticos, por lo que el hecho de que las acciones sanitarias asocien a los barrios pobres como productores de enfermedad podría tener consecuencias sociales y políticas indeseadas. En situaciones de amenaza, como la emergencia de una enfermedad, todas las comunidades tienden a organizar explicaciones dominantes en términos morales y políticos, a fin de restablecer el orden.

En términos morales, reivindicar la limpieza como ritual de purificación, lleva a culpabilizar por la enfermedad a personas que se consideran más pobres, menos educadas y externas al entorno social inmediato. Este doble mecanismo actuaría como sentimiento comunitario. Podría tener un efecto de distanciamiento en la percepción de riesgo del dengue (al atribuir la enfermedad a "otros" sin higiene) y de baja participación comunitaria en las acciones preventivas (al considerar que las acciones preventivas son terreno casi exclusivo de las instituciones oficiales de salud) (Caballero Hoyos et ál., 2006: 131).

\section{"Llevar el agua a los barrios"}

Entre 1998 y 2008 la red de agua tratada de Clorinda fue extendida a más y más barrios, sin adecuar a esta mayor demanda el sistema de captación en Puerto Pilcomayo ni la capacidad de las piletas de tratamiento, que fueron diseñadas en 1972. Los meses de mayor temperatura ambiente (entre diciembre y abril), y en los horarios de mayor temperatura, el suministro tiene baja presión de salida aun en los barrios cercanos a la planta de tratamiento y bombeo. La infraestructura de captación del agua cruda cuenta con un solo motor de bombeo. Al requerir mantenimiento o por fallas en el sistema de provisión de energía eléctrica, sale de servicio. Esto ocasiona cortes imprevistos en el suministro de agua, que en verano han llegado a durar treinta horas en el centro de la ciudad y dos días en los barrios periféricos.

En el caso del barrio Terete, a estas deficiencias generalizadas se suman otras tres características. Por un lado, el tanque maestro de abastecimiento se ubica en medio de un conjunto de barrios de viviendas sociales (se corresponden con la categoría censal viviendas tipo A) que, por poseer tanques elevados y baños con descarga, retienen y reservan gran cantidad de agua (ver mapa 1 con puntos críticos de la red de agua Clorinda). Por otro, topográficamente los terrenos del barrio están sobreelevados (64 
msnm promedio) respecto de la ubicación de planta de tratamiento (61 msnm). Finalmente, las conexiones ilegales son otra de las causas por las que la red pierde caudal, calidad y se corta más frecuentemente en el barrio. Estas situaciones empeoran el abastecimiento de agua potable en todo Terete, al punto de que las casas que no pueden proveerse de una bomba elevadora, tampoco instalan cañerías dentro de la casa. El abastecimiento de agua tratada se limita a colocar una canilla en un caño flexible que llega a la puerta de la vivienda, permaneciendo en la única posición en que sale agua: al ras del suelo. Esta situación ha generalizado el uso de tanques para abastecerse de agua en los 2000 lotes que conforman el barrio.

Los tanques donde se guarda agua en los peridomicilios tienen diferentes orígenes: hay toneles plásticos de alimentos reciclados y muchos tanques de fibrocemento. Algunos tanques tienen el nombre de un candidato político. Según testimonios, el candidato mismo los llevó al barrio en un camión durante una campaña y sus referentes entregaron a algunas familias un papelito que se canjeaba por el tanque.

\section{Historia líquida}

Clorinda es una ciudad húmeda: tiene un clima subtropical templado con precipitaciones promedio abundantes (1200 mm anuales), y su urbanización coloniza bajos de inundación del río Pilcomayo. El clima y la ubicación en las cercanías de la desembocadura del río Paraguay hicieron que las inundaciones fueran la experiencia fundacional de la "communitas" local. "Cuando llegaron las inundaciones, parecía que el Pilcomayo se tragaba a Clorinda", se evoca. Existen tres registros ominosos: uno en 1905 (Ciclo Húmedo 1870-1920), otro en 1983 y un tercero en 1992 (Ciclo Húmedo 1973-2020). La primera inundación no encontró urbanización, la segunda se contuvo con barricadas. La tercera, al encontrar un poblado urbanizado espontáneamente y con construcciones precarias, arrasó con todo y Clorinda fue noticia en el país al romperse una barricada levantada a la altura del Bolsón Grande, que la sumergió totalmente. Estos eventos ambientales habituaron a los pobladores a anegamientos periódicos, relocalización de barrios y construcción de barreras de defensa de las crecientes.

El barrio Terete se creó en 140 ha de tierras fiscales, sobreelevadas y alejadas del centro, para albergar a los primeros evacuados de las inundaciones de 1992. Este evento hidrológico fue determinante de la estructura de saneamiento y provisión de agua potable que tiene Clorinda hoy en día, ya que posibilitó, mediante el desembolso de un crédito del Banco Mundial, el diseño y construcción de un sistema de defensa de las inundaciones con estaciones de retrobombeo en toda la costa y viviendas para relocalizar la población damnificada. 
La construcción de viviendas como parte del programa de control de inundaciones implicó la proliferación de barrios de viviendas del tipo censal $A^{8}$, es decir, las que inciden sobre el índice de Necesidades Básicas Insatisfechas en la calidad de materiales de la vivienda y acceso al saneamiento básico (abastecimiento de agua tratada y eliminación de excretas). La provisión de agua tratada para consumo humano y eliminación de excretas por descarga de los inodoros hace que, comparativamente respecto de la situación antecedente, estas viviendas sean más demandantes de agua. La sustitución de las letrinas (ubicadas fuera de las habitaciones de la vivienda) por baño instalado (en contigüidad con el núcleo de habitaciones) implica una fuente de olor y suciedad que hace imprescindible a sus moradores contar con un excedente de agua para limpiarlos. Atendiendo a estas necesidades, en los barrios de viviendas para evacuados se construyeron grandes tanques de reserva $\left(60-100 \mathrm{~m}^{3}\right)$.

En la perspectiva de los políticos provinciales, la expansión de la red de agua se identifica como una cruzada contra la pobreza estructural estadísticamente registrable.

Sin embargo, simultáneamente, las políticas de gestión del agua potable eran claramente neoliberales: pasaron de considerarla un bien común o un derecho social a ponerle valor de mercancía. Desde la inundación de 1992 y hasta diciembre de 1995, la provisión de agua potable en Clorinda estuvo en manos de una empresa del Estado provincial. En 1996 fue entregada en concesión a Aguas de Formosa SA. Esta empresa privada consolidó el agua potable como un servicio arancelado, y a los ciudadanos como consumidores. Su gestión no realizó inversiones de infraestructura, se centró en instalar medidores y administrar lo que había. En el barrio afirman que fue durante la gestión de esta empresa privada cuando se vieron obligados a sacar los bombeadores manuales o eléctricos de agua subterránea y tapar los pozos. Aun con estas medidas tendientes a lograr el monopolio del aprovisionamiento, Aguas de Formosa SA no logró transformar la provisión de agua potable en un negocio rentable, y en 1998 se retiró de la concesión. Desde diciembre de 1998, la cooperativa de servicios públicos que ya administraba la telefonía, la televisión por cable, la envasadora de gas y la electrificación rural asumió la gestión de la recolección y tratamiento de aguas negras, el sistema captación de agua cruda, la planta de potabilización y la red de distribución de agua potable. En el momento del trabajo de campo, la cooperativa se encontraba apenas en condiciones de administrar su déficit y moras en el pago, sin poder planificar inversiones de ampliación.

En el barrio Terete el agua por red no llegó hasta el año 2000. Durante ocho años (1992-2000) los pobladores que no tenían perforación con bombeo hicieron fila frente

8 En los censos nacionales de Argentina se define como casa "tipo A" a la vivienda con salida directa al exterior (sus moradores no pasan por patios, zaguanes o corredores de uso común). En contraposición con la casa tipo B, que cumple por lo menos una de las siguientes condiciones: no tiene provisión de agua por cañería dentro de la vivienda; no dispone de retrete con descarga de agua; tiene piso de tierra u otro material precario. El resto de las casas es considerado como casas tipo A. 
a tanques comunitarios con un grifo. Con la llegada del agua por cañerías, los cortes y la falta de presión permanente en la red de agua generaron una sólida red de relaciones sociales. En fragmentos de las conversaciones abiertas con vecinos del barrio, encontramos disuelta una moral del derecho al agua, en el contexto de una ciudad y una política pública que todavía, con diferentes argumentos, la considera una mercancía. Si bien el deber indica que "El agua no se le niega a nadie" (entrevista Mbl), tampoco se le entrega en cantidad a cualquiera: están quieren comparten con parientes sanguíneos, otros solo con el vecino lindero, otros prefieren dar y pedir a compañeros que conocen del trabajo y llevarla en bidones a su casa, otros entre quienes "son gente del mismo político", otros dan solo si son niños los que piden. También hay vecinos que no tienen y no necesitan agua "con una jarra que convida la vecina" les basta. Mariel ${ }^{9}$, una de las vecinas que presta su canilla a los ocupantes de "la villita"10 frente a su casa, lo expresó así:

Ellos (una pareja de vecinos) me pidieron una conexión clandestina, pero son dos personas solas. Pero yo no le di. No tanto por lo clandestino. Si no porque ellos no tienen hijos chicos. Y uno no puede darles un privilegio a ellos. La gente que tiene 5, 6 hijos van a necesitar más que ellos... Eso es ser fresco, ¿no cierto? De qué me va a servir darle a uno y que los otros no tengan (...) Yo no pienso en hacer nada, ninguna mejora en el manejo del agua en mi casa. Porque mis hijos están todo el día con ellos. Y ¿qué?, ¿yo voy a tener y ellos no? (...) Yo no les quiero cobrar... tres, cuatro meses les cobré, pero después hay que andar y no te pagan. Saben por qué pienso así, porque cuando vine, yo también era así. De acá dos cuadras me daban en una casa que había agua de bomba. Por eso, yo me acuerdo como era, yo tenía al más chico de año y medio. Eso es lo que pienso yo. El agua no se le niega a nadie (Mbl, villita. 18/2/09).

\section{Sistemas de acopio de aguas}

La información analizada en este acápite surge de la base de datos generada por una encuesta aplicada a una muestra al azar de 61 unidades domésticas del barrio. Al mismo tiempo que algunas variables se volcaban como respuesta a las preguntas de la encuesta, se indagaban pautas de consumo, compra, acopio y temas propuestos por los entrevistados en relación con el agua, en una entrevista abierta que se registraba en un grabador digital. El análisis de las entrevistas abiertas mantenidas con $51 / 61^{11}$ de los responsables domésticos permitió organizar dieciocho sistemas de gestión de las aguas acopiadas en el peridomicilio.

Las unidades domésticas que componen la muestra de este estudio tienen viviendas en las que la moda estadística son tres cuartos además de baño y cocina. La cantidad

$9 \quad$ Nombre ficticio.

10 Es un asentamiento sin conexión a la red de agua, en terrenos hacia donde está creciendo la ciudad.

11 De los diez faltantes, tres fueron renuentes y de siete entrevistas no hay registro de audio. 
de miembros modal es de cinco integrantes. De modo que no presentan condiciones de hacinamiento crítico $^{12}$ (tres o más personas por cuarto en la vivienda, frente a 1,66 persona/cuarto en la muestra).

Las personas que se encargan del manejo del agua en los domicilios son, en su mayoría, mujeres de menos de 45 años y varones de entre 46 y 75 años. De esto podemos inferir la relativa colaboración de los varones en las familias que están en etapa de criar a sus hijos. Este dato permitiría repensar el género en la vigilancia y control del dengue, ya que varios trabajos recientes que analizan intervenciones asocian mujer-ama de casa con responsable del manejo del agua en forma acrítica (Chiaravallotti Neto, 1997; Chiaravallotti et ál., 2002).

Un 53 \% de las viviendas que integran la muestra corresponden a la categoría censal "Vivienda tipo b", principalmente por no tener agua por cañería dentro de la vivienda o tener uno o más ambientes con piso de tierra. Ranchos son el $5 \%$ de las viviendas y el resto, tipo $\mathrm{A}$.

En las unidades domésticas estudiadas, cada tipo de agua (tratada, de lluvia o subterránea) tiene una forma de recolección, de cuidado (se la tapa o no, se la clora o no, se limpia o no el tanque, con qué materiales, cómo y con qué periodicidad) y de uso (consumo humano; higiene personal; lavar ropa, vajilla o casa; balde al inodoro o letrina; riego).

Las unidades de análisis en las que había más de un tanque constituyen un ejemplo fehaciente de esto (rec 25 y 26; 13 y 21; 45 y 59): en las entrevistas abiertas pudo captarse que la forma de recarga; los usos prioritarios y las frecuencias y técnicas de limpieza son diferenciados por el origen del agua almacenada. El $70 \%$ de los entrevistados manifestó que no mezcla agua de diferentes fuentes en un mismo recipiente de acopio.

Producto de la escasez, pero también de algunas preferencias de gusto, las aguas de consumo y uso se ordenan en tres tipologías: a) sin acopio de agua de lluvia, b) con acopio de agua de lluvia y c) con acopio de aguas subterráneas. Estos tipos son sincrónicos, describen el arreglo de manejo de aguas que la unidad doméstica tenía en el momento de la entrevista. La tabla 1 muestra todos los estados posibles para cada tipo de agua encontrados en el relevamiento.

El tipo a) sin acopio de agua de lluvia agrupa el $47 \%$ de la muestra. En estas viviendas se guarda agua tratada y se recarga el tanque objeto de la intervención sanitaria cuando no se corta el suministro y la red tiene presión. El tipo b) con acopio de agua de lluvia agrupa el 37 \% de los casos. En estos domicilios se guarda, además de agua tratada, agua de lluvia, en tanques separados. Excepcionalmente el dueño de un tanque semienterrado de 5000 litros (aljibe) guardaba solo agua de lluvia. Finalmente, un $16 \%$ de las unidades domésticas reconoció utilizar agua subterránea.

12 Indicador de NBI. 
Todos ellos la consideraban un recurso "para (abastecer a) los vecinos" no conectados a la red, o disponible en casos extremos de escasez, ya que "el agua no se le niega a nadie" (rec. 5). Solo un caso la prefería para consumo humano en su unidad doméstica.

En lo que respecta al control vectorial, las particularidades de la recarga y el uso continuo del agua de los recipientes dificulta que se mantenga la concentración necesaria del larvicida, que se realicen periódicamente acciones de limpieza y que se mantengan tapados. En el caso de los tanques de fibrocemento, al taparlos y destaparlos continuamente, la tapa se rompe y se descarta. Solo una de las unidades domésticas, que tenía bomba elevadora eléctrica, mantenía tapado el tanque de acopio. El caso de los que guardan agua de lluvia presenta la particularidad de que asocian la limpieza del tanque como actividad previa al acopio. En ambos casos, el material de los tanques es una variable que condiciona la eficacia de la remoción de criaderos en las paredes del tanque. En el fibrocemento y otros materiales porosos es especialmente difícil.

En la indagación cualitativa, se pudo precisar que la frecuencia de lavado depende de dos variables: el consumo del agua y el "ver sucio" el recipiente. Los registros de audio enuncian como suciedad del tanque:

-Tierra en el fondo, "cuando viene el agua de red después de un corte, trae tierra y eso ensucia el tanque";

-"Las marcas de las manos de los chicos que meten recipientes para sacar agua del tanque";

-"El moho, verdín o eso verde que se le hace por arriba o abajo y que ya no sale en los tanques de fibrocemento viejos".

Las personas que contestaron que lo limpian "antes que llueva" son las que acopian agua de lluvia. Quienes también informaron que "esperan que caiga primero una buena cantidad de agua, que lave la suciedad del techo antes de comenzar a guardar en el tanque". Sin embargo, no todas las personas que guardan agua de lluvia tienen esta práctica, otras prefieren lavarlo no bien lo ven sucio, o cuando les queda poca agua lo vuelcan, lo limpian y esperan con el tanque limpio la próxima tormenta.

Las respuestas estructuradas a la secuencia de acciones que los entrevistados describieron como "lavar el tanque" fueron reagrupadas según intereses teóricos de la investigación. Los criterios de agregación fueron: que use elementos como escobas, cepillos, esponjas o trapos ásperos para raspar la pared del tanque, que permitan desprender la suciedad adherida; que sume a esa acción mecánica algún producto químico de limpieza como lavandina o detergente y que enjuague o no enjuague esos productos. Esto último porque en las entrevistas abiertas aparecían referencias a que preferían no enjuagar el último rociado de lavandina, considerando que era un cuidado para el agua. Mientras que para otros entrevistados, el cloro era la principal causa de rechazo al agua potable y la razón por la que preferían consumir agua de lluvia. 
El $90 \%$ de los entrevistados informó usar escobas, cepillos, esponjas o trapos ásperos para la acción de limpieza. Muchos de ellos incluso, durante la entrevista, nos mostraron cuál era el cepillo o escoba gastada que guardaban para limpiar el tanque.

El 56 \% usa además de la acción mecánica, algún producto químico, con preferencia la lavandina. Un $22 \%$ de quienes usan productos químicos dejan la lavandina del último enjuague como forma de cuidar el agua.

En lo que respecta a la percepción nativa de la eficacia del agente larvicida, el $77 \%$ lo consideró suficiente. Entre quienes consideraron que fallaba, la principal razón fue que el tanque permanecía destapado. Como señalaron también estudios anteriores (Fajardo et ál., 2001; Lefevre et ál., 2003) la aplicación del agente químico relaja otras medidas de cuidado y prevención que implican voluntad o cambio de prácticas familiares o comunitarias. El 51 \% de los hogares cuyos tanques reciben la aplicación del larvicida no hacen nada más para evitar la presencia de larvas o mosquitos. Entre los modos de aplicación del químico, en perspectiva del actor se prefirió la aplicación dentro de una bolsa zipper, porque a diferencia de la aplicación con cuchara "podía verse como seguía actuando el remedio" aun cuando el tanque era recargado.

$\mathrm{Al}$ analizar los usos a los que se destina el agua que se acopia, sistematizando tanto el primero como el segundo, los hogares de la muestra consideran que el consumo humano es el primer uso del agua que acopian, seguido por la limpieza de la casa, la ropa o la vajilla. Esta información suministrada por la encuesta es coherente con los datos de las entrevistas en profundidad dentro y fuera del barrio que caracterizan el sistema de agua potable local como extendido pero insuficiente.

\section{Reflexión final}

Caballero Hoyos et ál. (2006); Lefevre et ál. (2003 y 2004) y Whiteford (1997) realizaron análisis tendientes a complejizar las explicaciones de la causalidad social de las epidemias y el control del dengue a nivel focal en México, Brasil y República Dominicana, precisando representaciones sociales y variables involucradas en el momento de implementar una vigilancia y control participativos eficaces. Mientras los estudios de casos de México y Brasil centraron las fallas del control en representaciones de los gestores y la comunidad, el estudio en Dominicana mostró la escasa motivación a participar de las acciones de control por descrédito en la política (lo que Whiteford denomina, "la mala unión"). En este sentido, Suárez et ál. (2009) mostraron cómo, aun cuando el control del dengue es prioritario en las políticas públicas, en dos pueblos de Colombia la gente tolera y administra la presencia del vector y el padecimiento como un hecho cotidiano y un riesgo menor.

En continuidad con estas líneas de trabajo, la información presentada en este artículo muestra la necesidad de acompañar las medidas de control focal comunitario de criaderos del vector con estudios microsociales (del barrio o la vecindad) con 
metodologías cualitativas, tendientes a captar variables discontinuas que puedan estar incidiendo sobre la eficiencia de esas acciones.

Varios estudios señalaron limitaciones del control larval del vector en los ciclos focales. El artículo de Stoddard et ál. (2013) señaló que, dada la limitada capacidad de movimiento del vector, los esfuerzos de prevención centrados en el control del mosquito tienen un éxito limitado, por lo que, según demuestra, es relevante estudiar simultáneamente las interacciones humanas de rutina (traslados casa-casa o casa trabajo) como forma de dispersión del patógeno. Fajardo et ál. (2001) han llamado la atención de las limitaciones del control químico con larvicida por el efecto de "falsa confianza". El estudio de Garelli et ál. (2009) analizó las limitaciones de la residualidad frente al recambio de agua por recarga continua de los tanques.

Por otra parte, las investigaciones de Caprara et ál. (2009) en el nordeste y de Mondini y Chiaravallotti Neto (2007) en el sudeste de Brasil muestran que la dispersión y abundancia vectorial es independiente del nivel de ingreso de las familias. Sin embargo, las conclusiones a las que arriban Caprara et ál. (2009) son reveladoras: independientemente del ingreso, todas las áreas de Fortaleza estudiadas tienen déficits en la provisión de agua, solo que mientras los sectores de mayor poder adquisitivo lo resuelven comprando una bomba eléctrica, los de menores ingresos llenan sus patios con tanques y tachos donde proliferan los criaderos del vector, por lo que el riesgo de infección se distribuye reinscribiendo desigualdades.

El presente estudio señala que la reproducción acrítica de un modelo de control focal puede opacar la comprensión de las razones estructurales por las que un grupo social guarda agua en su patio. Como desarrollamos al analizar el Discurso del Sujeto Colectivo de los agentes sanitarios, cuando las medidas de control centradas en el compromiso comunitario y la acción colectiva presentan fisuras, deben replantearse. En esta instancia, en el caso de estudio, las críticas de los agentes de prevención se orientaron a culpar de falta de compromiso a los ciudadanos, opacando la comprensión de las carencias estructurales que eran la última causa. Para eliminar definitivamente los criaderos en los recipientes $B$ y $F$ no es necesario un cambio cultural o intensificar los ciclos focales. Bastaría con ampliar las capacidades de captación y tratamiento del sistema de agua por red de la ciudad. Por lo expuesto aquí es que consideramos muy relevante acompañar la implementación de los programas de vigilancia y control vectorial con estudios microsociales en campo.

\section{Agradecimientos}

El trabajo de campo fue realizado en febrero de 2009 con financiamiento y colaboración de la sede Clorinda de la Fundación Mundo Sano y el Lic. Diego Weinberg. Fernando Garelli propuso el estudio sociológico de los hogares que tenían los tanques de agua en que estudiaba la residualidad del larvicida. 


\section{Mapa}

1

Mapa 1 Ubicación puntos críticos red de aqua potable de Clorinda.

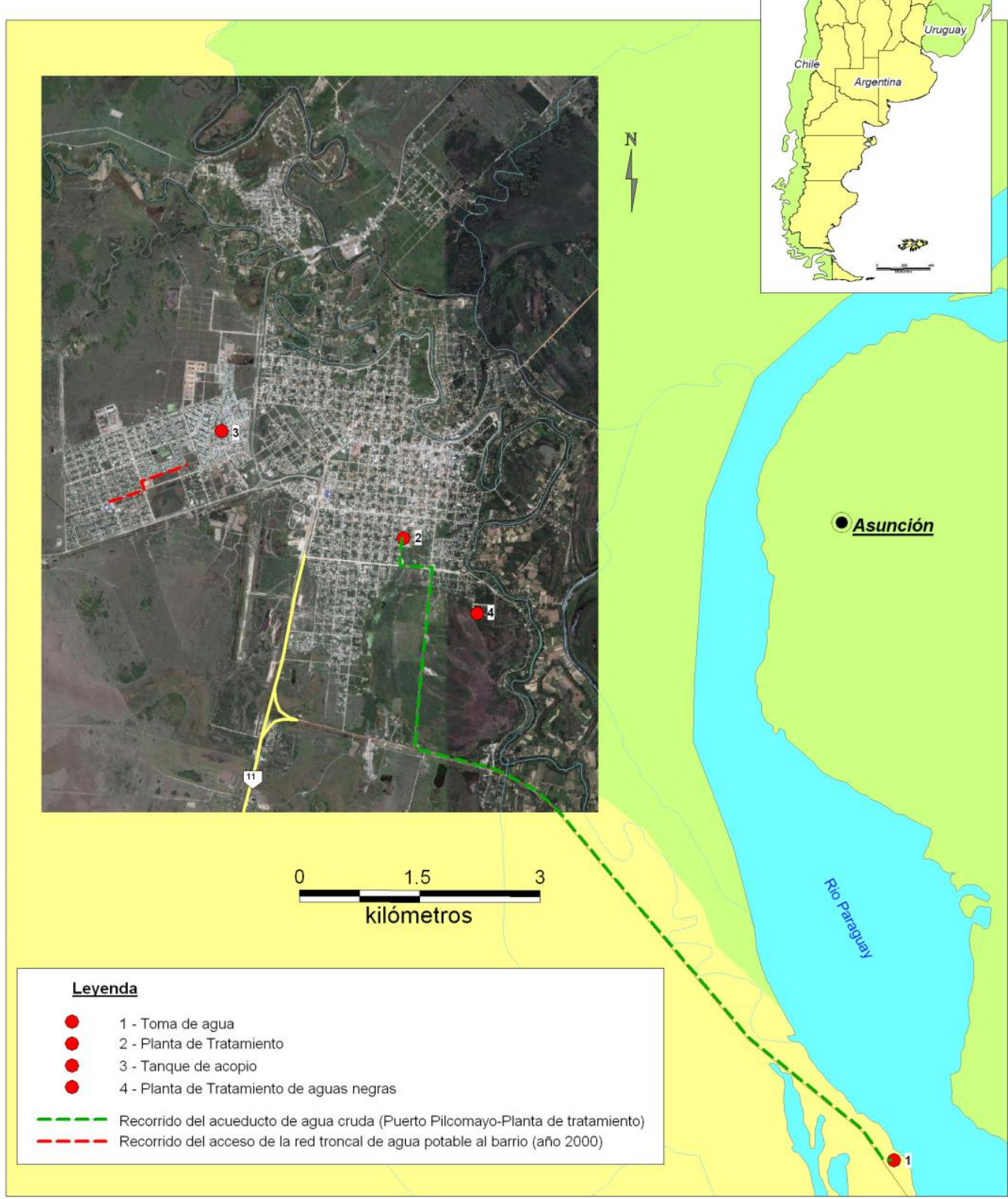


Tabla 1

Tipos de aguas que se acopian en los patios del barrio y tipos de agua preferidas para consumo en Terete, Clorinda

\begin{tabular}{|c|c|c|c|}
\hline Agua de red & Agua de lluvia & $\begin{array}{c}\text { Aguas } \\
\text { subterráneas }\end{array}$ & \begin{tabular}{ll}
\multicolumn{1}{c}{ Agua } & preferida \\
para & consumo \\
humano & \\
\end{tabular} \\
\hline $\begin{array}{l}\text { Pico en el lote sin } \\
\text { tanque elevado Sin } \\
\text { agua de red acopiada } \\
\text { en recipientes B -F en } \\
\text { patio. }\end{array}$ & $\begin{array}{l}\text { Guarda con } \\
\text { conexión techo zinc, } \\
\text { canaleta - recipiente } \\
\text { B o F }\end{array}$ & $\begin{array}{l}\text { Bomba manual en } \\
\text { funcionamiento }\end{array}$ & $\begin{array}{c}\text { Potable de red } \\
\text { desde pico en el lote }\end{array}$ \\
\hline $\begin{array}{l}\text { Pico dentro de la } \\
\text { casa sin tanque } \\
\text { elevado ni motor } \\
\text { bombeo. Sin agua de } \\
\text { red acopiada en } \\
\text { recipientes B }-\mathrm{F} \text { en } \\
\text { patio }\end{array}$ & No guarda & $\begin{array}{l}\text { Bomba eléctrica } \\
\text { en funcionamiento }\end{array}$ & $\begin{array}{l}\text { Potable de red } \\
\text { desde pico en el } \\
\text { interior de la vivienda }\end{array}$ \\
\hline $\begin{array}{l}\text { Pico dentro de la } \\
\text { casa con tanque } \\
\text { elevado y motor } \\
\text { bombeo. Sin agua de } \\
\text { red acopiada en } \\
\text { recipientes B -F en } \\
\text { patio. }\end{array}$ & & $\begin{array}{l}\text { Bomba manual / } \\
\text { perforación } \\
\text { abandonada } \\
\text { o que nunca } \\
\text { tuvieron perforación }\end{array}$ & $\begin{array}{l}\text { Potable de red } \\
\text { desde recipiente tipo } \\
\mathrm{B} \text { en patio o desde } \\
\text { balde en interior } \\
\text { vivienda }\end{array}$ \\
\hline 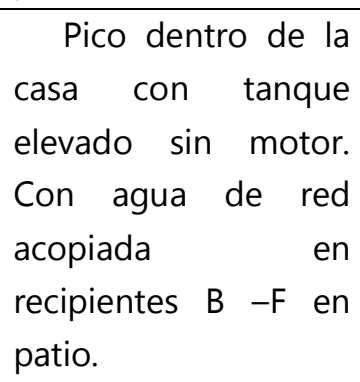 & & Sin perforación & $\begin{array}{l}\text { Potable de red } \\
\text { desde pico en } \\
\text { conexión del vecino }\end{array}$ \\
\hline $\begin{array}{l}\text { Pico en el lote y } \\
\text { guarda en recipiente } \\
\text { tipo B y/o } F \text { en el } \\
\text { patio. }\end{array}$ & & & Agua subterránea \\
\hline $\begin{array}{l}\text { Pico dentro de la } \\
\text { casa, tanque elevado, } \\
\text { motor de bombeo, } \\
\text { cisternas y recipientes } \\
\text { B o F en el patio }\end{array}$ & & & $\begin{array}{l}\text { Agua de lluvia } \\
\text { desde recipiente tipo } \\
\text { B en patio }\end{array}$ \\
\hline $\begin{array}{l}\text { Sin conexión pero } \\
\text { guarda agua potable }\end{array}$ & & & \\
\hline
\end{tabular}




\begin{tabular}{|l|l|l|l|}
\hline $\begin{array}{l}\text { en recipiente tipo B o } \\
\mathrm{F}\end{array}$ & & \\
\hline $\begin{array}{l}\text { Sin conexión a la } \\
\text { red }\end{array}$ & & \\
\hline & $\begin{array}{l}\text { Sistema Mbl (recipientes } \mathbf{5} \text { red, } \mathbf{6} \text { red, } 10 \text { red; } 11 \text { red; } 28 \text { red ; } 33 \\
\text { red; } \mathbf{3 8} \text { red; } 39 \text { red; } \mathbf{5 4} \text { red; } \mathbf{6 2} \text { red en este caso el recipiente está } \\
\text { dentro de la casa) }\end{array}$ \\
\hline
\end{tabular}

\section{BIBLIOGRAFÍA}

Caballero Hoyos, Ramiro; Teresa Torres López, Francisco Chong Villarreal, Alicia Pineda; Lucatero, Marlene Altuzar González y Berenice López Coutiño (2006). Concepciones culturales sobre el dengue en contextos urbanos de México. Rev. Saúde Pública. 40: 1 126-133.

Caprara, Andrea, Lima, José Wellington de Oliveira, Marinho, Alice Correia Pequeno, Calvasina, Paola Gondim, Landim, Lucyla Paes, \& Sommerfeld, Johannes (2009). Irregular water supply, household usage and dengue: a bio-social study in the Brazilian Northeast. Cadernos de Saúde Pública, 25 (Suppl. 1), S125-S136. Retrieved July 12, 2013, from http://www.scielosp.org/scielo.php?script=sci_arttext\&pid=S0102$311 X 2009001300012 \& \mid n g=e n \& t$ lng =en. 10.1590/S0102-311X2009001300012.

Chiaravalloti Virgínia Baglini ;Maria Sílvia de Morais; Francisco Chiaravalloti Neto; Danaé Teresinha Conversan; Ana Maria Fiorin; Angelita Anália Carniel Barbosa; Amena Alcântara Ferraz (2002) Avaliação sobre a adesão às práticas preventivas do dengue: o caso de Catanduva, São Paulo, Brasil Cad. Saúde Pública, Rio de Janeiro, 18(5): 13211329, set-out.

Chiaravalloti Neto, F; Maria Silvia de Moraes; Maria Aparecida Fernández (1998) Avaliação dos resultados de atividades de incentivo à participação da comunidade no controle da dengue em um bairro periférico do Município de São José do Rio Preto, São Paulo, e da relação entre conhecimentose práticas desta população. Cad. Saúde Pública, Rio de Janeiro, 14 (Sup. 2): 101-109

Chiaravalloti Neto, Francisco (1997) Conhecimentos da população sobre dengue, seus vetores e medidas de controle em São José do Rio Preto, São Paulo. Cad. Saúde Públ., Rio de Janeiro, 13(3): 447-453, jul-set.

Douglas Mary (1994) Essays in cultural theory. In: Risk and blame London: Routledge; 1994. p. 3-21.

Fajardo, Paulina; Carlos Arturo Monje, Gladys Lozano, Orlando Realpe y Luis Eduardo Hernández (2001). Nociones populares sobre "dengue"y "rompehuesos", dos modelos de la enfermedad en Colombia 2001. In: Rev Panam Salud Publica/Pan Am J Public Health 10(3), 2001. 
Garelli, F. M.; Espinosa, M. O.; Weinberg, D.; Trinelli M. A.; Gürtler, R. E. (2011) Water Use Practices Limit the Effectiveness of a Temephos-Based Aedes aegypti Larval Control Program in Northern Argentina. PLoS Negl Trop Dis 5(3): e991. doi:10.1371/journal.pntd.0000991

Lefevre, F. y Cavalcanti Lefevre, A. M. (2007). The collective Subject that speaks. In: Interface. Vol. 3 N. ${ }^{\circ}$ Se. Botocatu.

Lefevre, Fernando; Lefevre, Ana Maria Cavalcanti; Scandar R, Sirle Abdo Salloum e Yassumaro, Sueli (2004). Representações sociais sobre relações entre vasos de plantas e o vetor da dengue. Rev. Saúde Pública [online]. vol. 38, no. 3, pp. 405-414.

Lefevre, Ana Maria Cavalcanti; Fernando Lefevre; Sirle Abdo Salloum Scandar; Sueli Yasumaro; Susy Mary do P. Sampaio (2003). Representações dos agentes de combate ao Aedes aegypti sobre a estratégia de retirada do inseticida nas ações de controle do vetor. Revista Brasileira de Epidemiologia: 360-372.

Manderson, L.; Aaby, P. (1992). Can rapid anthropological procedures be applied to tropical diseases? In: Health policy and planning. Mar. 7(1): 46-55.

Mondini A.; Chiaravalloti Neto F. 2007 Socioeconomic variables and dengue transmission Rev Saúde Pública; 41(6): 923-30, Dec.

Passos, Afonso Dinis Costa; Rodrigues, Eugênia Maria Silveira; Dal-Fabbro, Amaury Lelis (1998) A experiência hacer hacer el control del dengue em Ribeirão Preto, São Paulo, Brasil 1990. Cad. de Saúde Pública; 14 (Sup. 2): pp. 123-128.

Scrimshaw, S. \& Hurtado, E., (1987). Rapid Assesment Procedures for Nutrition and Primary Health Care: Antropological Approaches to Improving Programme Effectiveness. Los Angeles: UCLA Latin American Center/Tokyo: United Nations University.

Schweigmann, Nicolas, Rizzotti, Andrea, Castiglia, Gabriela, Gribaudo, Fabio, Marcos, Edgardo, Burroni, Nora, Freire, Gabriela, D'Onofrio, Vanesa, Oberlander, Sara, Schillaci, Héctor, Gómez, Sandra, Maldonado, Santiago, \& Serrano, Claudia. (2009). Información, conocimiento y percepción sobre el riesgo de contraer el dengue en Argentina: dos experiencias de intervención para generar estrategias locales de control. Cadernos de Saúde Pública, 25(Suppl. 1), S137-S148. Retrieved July 12, 2013, from http://www.scielosp.org/scielo.php?script=sci_arttext\&pid=S0102$311 X 2009001300013 \&$ Ing=en\&tIng=es. 10.1590/S0102-311X2009001300013.

Stoddard, S. T., Brett M. Forshey, Amy C. Morrison, Valerie A. Paz-Soldan, Gonzalo M. Vazquez-Prokopec, Helvio Astete, Robert C. Reiner, Jr., Stalin Vilcarromero, John P. Elder, Eric S. Halsey, Tadeusz J. Kochel, Uriel Kitron,Thomas W. Scott 2013 House-tohouse human movement drives dengue virus transmissionProc Natl Acad Sci USA. 2013 January 15; 110(3): 994-999. Published online 2012 December 31. http://www.nlm.nih.gov/pmc/articles/PMC3549073/?tool=pubmed

Suárez, Roberto, González, Catalina, Carrasquilla, Gabriel, \& Quintero, Juliana. (2009). An ecosystem perspective in the socio-cultural evaluation of dengue in two Colombian towns. Cadernos de Saúde Pública, 25(Suppl. 1), S104-S114. Retrieved July 12, 2013, 
De Prácticas y discursos/ Universidad Nacional del Nordeste/ Centro de Estudios Sociales

from

http://www.scielosp.org/scielo.php?script=sci_arttext\&pid=S0102-

$311 X 2009001300010 \&|n g=e n \& t| n g=e n .10 .1590 /$ S0102-311X2009001300010.

Whiteford, L. M. (1997) The ethnoecology of dengue fever. In: Medical Anthropology Quarterly. New series. Vol. 11: 2 Jun. 202-223. 